\title{
Effectiveness of a financial incentive to physicians for timely follow-up after hospital discharge: a population-based time series analysis
}

\author{
Lauren Lapointe-Shaw MD, Muhammad Mamdani PharmD MPH, Jin Luo MD MSc, \\ Peter C. Austin PhD, Noah M. Ivers MD PhD, Donald A. Redelmeier MD MSHSR, Chaim M. Bell MD PhD
}

Cite as: CMAJ 2017 October 2;189:E1224-9. doi: 10.1503/cmaj.170092

\begin{abstract}
BACKGROUND: Timely follow-up after hospital discharge may decrease readmission to hospital. Financial incentives to improve follow-up have been introduced in the United States and Canada, but it is unknown whether they are effective. Our objective was to evaluate the impact of an incentive program on timely physician follow-up after hospital discharge.
\end{abstract}

METHODS: We conducted an interventional time series analysis of all medical and surgical patients who were discharged home from hospital between Apr. 1, 2002, and Jan. 30, 2015, in Ontario, Canada. The intervention was a supplemental billing code for physician follow-up within 14 days of discharge from hospital, introduced in 2006. The primary outcome was an outpatient visit within 14 days of discharge. Secondary outcomes were 7-day follow-up and a composite of emergency department visits, nonelective hospital readmission and death within 14 days.

RESULTS: We included 8008934 patient discharge records. The incentive code was claimed in $31 \%$ of eligible visits by $51 \%$ of eligible physicians, and cost $\$ 17.5$ million over the study period. There was no change in the average monthly rate of outcomes in the year before the incentive was introduced compared with the year following introduction: 14-day follow-up (66.5\% v. $67.0 \%$, overall $p=0.5), 7$-day follow-up $(44.9 \%$ v. $44.9 \%$, overall $p=$ $0.5)$ and composite outcome (16.7\% v. $16.9 \%$, overall $p=0.2$ ).

INTERPRETATION: Despite uptake by physicians, a financial incentive did not alter follow-up after hospital discharge. This lack of effect may be explained by features of the incentive or by extraphysician barriers to follow-up. These barriers should be considered by policymakers before introducing similar initiatives.
$\mathbf{R}$

eadmissions after hospital discharge are common, occurring for about $14 \%$ of patients in the United States at 30 days after discharge and costing $\$ 41$ billion annually. ${ }^{1}$ How much hospital readmissions may be preventable through improved continuity of care is uncertain. ${ }^{2-4}$ The period following hospital discharge is marked by a high risk of adverse events and omissions of care, including failure to follow-up on in-hospital testing or implement a recommended work up. ${ }^{5-8}$ Timely followup may mitigate some of these risks by providing an opportunity for education, medication reconciliation, review of hospitalist recommendations and recognition of clinical deterioration. Early visits after hospital discharge reduce readmissions in high-risk patients, such as those who were admitted to hospital for chronic obstructive pulmonary disease or heart failure. ${ }^{9-13}$ Results have been mixed in other populations. ${ }^{14-19}$
In 2009, Jencks and colleagues reported that only half of all patients in the Medicare fee-for-service program who had been discharged from hospital had seen a physician before their readmission. ${ }^{20}$ Possible reasons for lack of timely follow-up include patient health literacy, mobility, provider accessibility and awareness of patient's admission to hospital. ${ }^{21-23}$

It is uncertain whether financial incentives to physicians improve quality of care. ${ }^{24-26}$ However, such incentives may be one way to increase rates of early follow-up. In 2013, the Centers for Medicare and Medicaid Services introduced transitional care management codes to the US, which provide additional reimbursement to physicians offering early patient follow-up. ${ }^{27}$ In 2006, the Ontario Ministry of Health and Long-Term Care introduced a similar incentive, by providing a $\$ 25.00$ premium for an outpatient visit within 2 weeks of hospital discharge. ${ }^{28}$ It is 
unknown whether such incentives are effective in their proximate goal, to increase rates of follow-up, or in their downstream goal of reducing readmissions. Our primary objective was to evaluate the impact of this incentive on rates of timely physician follow-up.

\section{Methods}

\section{Setting and design}

We conducted a population-based retrospective time series study of patients discharged from acute care inpatient beds between Apr. 1, 2002, and Jan. 30, 2015, in Ontario, Canada.

\section{Data sources}

The multiple databases at the Institute for Clinical Evaluative Sciences (Toronto, Ont.) contain coded linked health administrative data for all Ontario residents. This includes information on all admissions to hospital for acute care in the province, ${ }^{29}$ all visits to the emergency department, ${ }^{30}$ billing claims submitted by physicians to the public health insurance program, ${ }^{31}$ demographic information and vital statistics. ${ }^{32}$

\section{Study population}

We identified all patients discharged to the community from an acute care hospital between Apr. 1, 2002, and Jan. 30, 2015. We excluded newborns, patients admitted for an obstetrical delivery or a psychiatric problem, patients receiving palliative care during the index hospital admission or patients with a length of stay greater than 100 days. In addition, we excluded records that were missing age or gender, or had an invalid Ontario postal code or invalid death date (Appendix 1, available at www.cmaj.ca/lookup/ suppl/doi:10.1503/cmaj.170092/-/DC1, supplementary Figure 1).

\section{Exposure}

The incentive fee code introduced in October 2006 allows an additional $\$ 25.00$ for a physician visit in an office or home setting within 2 weeks of hospital discharge. ${ }^{28}$ The premium is not offered for visits in long-term care facilities, following admission for obstetrical delivery, routine in-hospital care of the newborn or day surgery. The incentive code is supplemental to commonly used primary care codes that range in value from $\$ 21.50$ to $\$ 104.80$ (Appendix 1, supplementaryTable 1). Incentive payment is received between 3 weeks and 2 months after submission, with other feefor-service claims. The existence of the incentive was communicated to physicians through a single mailed bulletin, dated Oct. 1, 2006, and was included in the updated physician fee schedule. ${ }^{28}$

\section{Patient characteristics}

We evaluated baseline characteristics such as patient age, sex, hospital length-of-stay, Charlson comorbidity index score, ${ }^{33}$ socioeconomic status, previous health care usage (visits to the emergency department, hospital admissions, outpatient visits and home care visits), and whether the index admission was elective or urgent.

\section{Outcomes}

The primary outcome was follow-up with any physician within 14 days of discharge from hospital. We included visits if they occurred in an office or home setting and excluded medical imaging or laboratory testing. Secondary outcomes included follow-up at 7 days, as well as a composite of return to the emergency department, nonelective readmission to hospital or death within 14 days.

\section{Statistical analysis}

We compared the characteristics of patients who did or did not reach the primary outcome using standardized differences (Std. Diff.). Where baseline characteristics differed by at least $10 \%$, we plotted them over time.

\section{Time-series analysis of primary and secondary} outcomes

We reported primary and secondary outcomes by month as a proportion of all discharges and plotted these values over time. We used autoregressive integrated moving average (ARIMA) methods to model these monthly proportions, accounting for autocorrelation, seasonality and trends. We used an interventional term to test for the effect of the introduction of the incentive on the outcome, over and above any background trends. We accounted for an apparent shift in follow-up rates in October 2015 with an additional interventional term. Model selection was guided by visual inspection of correlograms. We assessed stationarity by using the augmented Dickey-Fuller test, and autocorrelation at various lags was assessed using the Ljung-Box $\chi^{2}$ test. ${ }^{34}$ All significance testing was 2 -tailed with a significance threshold set at $p<0.05$. Analyses were performed using SAS/ETS software, version 9.4 (SAS Institute Inc.).

\section{Sensitivity and subgroup analyses}

To determine whether results were sensitive to the outcome definition, we conducted an analysis in which the outcome was either 14-day follow-up with a previously known physician or primary care physician assigned to the patient. Previously known physicians had at least 1 office or home visit with the patient in the year before discharge from hospital. Primary care physicians were assigned using tables from the Ontario Client Agency Program Enrolment (for formally rostered patients) or through virtual rostering with commonly used primary care codes (Appendix 1, supplementary Table 2). ${ }^{35}$ We also performed analyses stratified by patient age at discharge $(<18,18-64$ and $\geq 65 \mathrm{yr}$ of age) and for discharges following an urgent admission.

\section{Ethics approval}

This project was approved by the Research Ethics Board of Sunnybrook Health Sciences Centre.

\section{Results}

We included data on 8008934 patient discharges from 206 acute care hospitals. Of these, 550742 discharges (6.9\%) occurred on the same day as a follow-up visit. By 14 days after discharge, 5284742 patients (66.0\%) had follow-up with any physician, 4059337 (50.7\%) had follow-up with a previously known physician and 2736785 (34.2\%) had follow-up with their primary care 
physician. Patients had follow-up within 14 days after discharge by 33676 distinct physicians. In the same time period, 1369382 $(17.1 \%)$ reached the composite outcome of return to emergency department, nonelective readmission or death (Figure 1).

\section{Patient characteristics}

Patients who did not have a follow-up visit within 14 days of discharge from hospital had fewer previous outpatient visits (Std. Diff. 0.39), comorbidities (Std. Diff. 0.14), a shorter lengthof-stay (Std. Diff. 0.12) and were more likely to be assigned to a fee-for-service primary care physician (Std. Diff. 0.10). Over our study period, the proportion of patients with no comorbid diagnoses gradually decreased from $52.5 \%$ to $47.4 \%$ (Appendix 1 , supplementary Figure 2). Previous outpatient visits and length-of-stay remained stable throughout the study (Appendix 1, supplementary Figure 3; median length-of-stay was consistently $3 \mathrm{~d}$ ). The proportion of discharged patients assigned to an enhanced fee-for-service primary care physician increased from $18.2 \%$ to 40.0\% in 2005 (Appendix 1, supplementary Figure 4).

\section{Incentive uptake}

There was rapid uptake of the incentive in the first month following its introduction, with $19 \%$ of eligible visits accompanied by an incentive claim. Thereafter, this proportion gradually increased to $40.9 \%$ by January 2015 (overall proportion $31.3 \%$, monthly median $32.4 \%$, Figure 2). Since its introduction, the incentive was claimed within 2 weeks of discharge a median of 7023.5 times (interquartile range [IQR] 5982.25-7893) per month for a total cost of $\$ 17.5$ million (average $\$ 2.1$ million/yr). In the most recent year studied (2014), the incentive cost $\$ 2.7$ million.

There were 10057 distinct physicians who claimed the incentive in our cohort, which was $50.9 \%$ of the 19742 physicians who claimed eligible services. Of the physicians performing eligible services (monthly median $n=$ 7897 [IQR 7674-8304]), a median of $40.8 \%$ (IQR 35.6\%-44.2\%) claimed the incentive each month. the incentive code.

\section{Effect of incentive on outcomes}

The incentive had no significant effect on 14-day physician followup (monthly average of $66.5 \%$ in the year before incentive introduction, $67.0 \%$ in the year following incentive introduction; $p=0.5$ for intervention effect; Figure 3) or 7-day physician follow-up (44.9\% in the year before the incentive, $44.9 \%$ in the year following the incen-

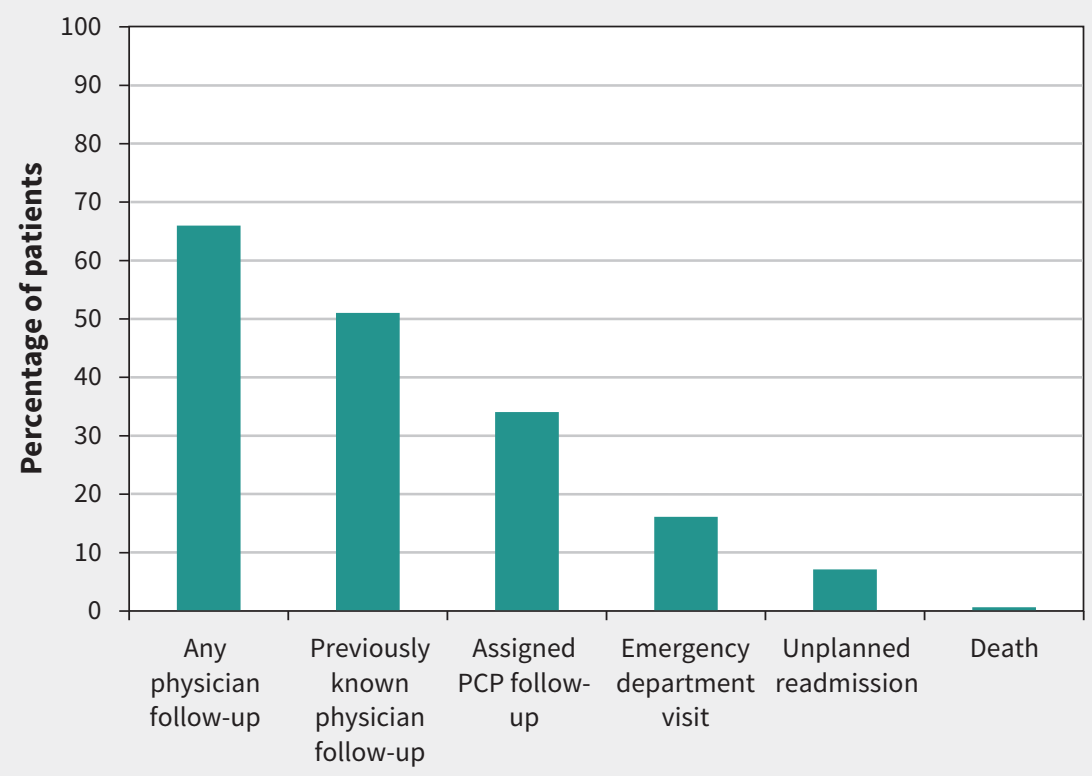

Outcome measures after hospital discharge

Figure 1: Overall proportions of 14-day outcome measures after patients were discharged from hospital. $\mathrm{PCP}=$ primary care physician .

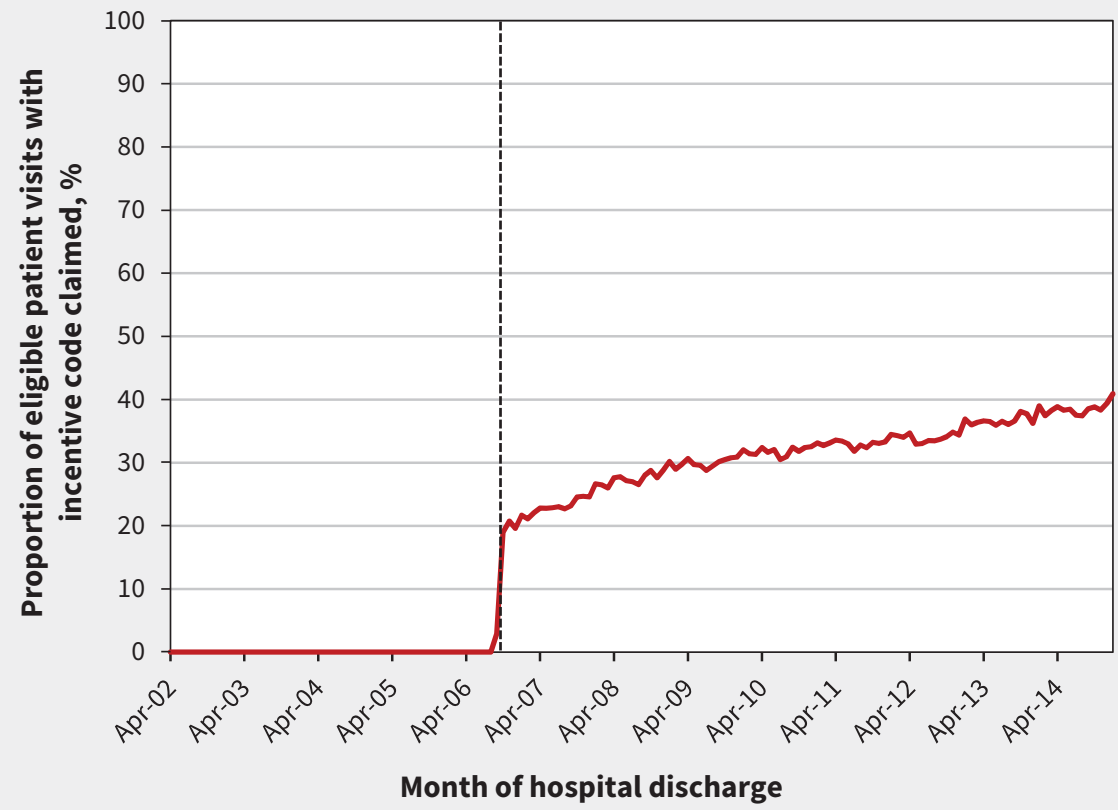

Figure 2: Uptake of the incentive code, by month of discharge. Broken line indicates the introduction of 
tive; $p=0.5$ for intervention effect; Figure 3 ). There was no significant change following incentive introduction in the proportion of patients who experienced the composite outcome (monthly average of $16.7 \%$ in the year before the incentive, $16.9 \%$ in the year following the incentive, $p=0.2$ for intervention effect; Figure 4).

\section{Sensitivity and subgroup analyses}

There was no change in 14-day follow-up rates after incentive introduction when the outcome definition was changed to follow- up with a previously known physician $(p=0.6)$ or assigned primary care physician ( $p=0.5$ ) (Appendix 1, supplementary Figure 5).

In patients with an urgent index admission, and across all patient age categories, there was no change in 14-day physician follow-up after the incentive was introduced $(p=0.8$ for urgent patients, $p=0.3$ for age $<18 \mathrm{yr}, p=0.9$ for age $18-64 \mathrm{yr}, p=0.5$ for age $\geq 65$ yr; Appendix 1, supplementary Figures 6-9).

Similarly, physicians in the highest quartile of uptake of the incentive did not show a significant change in follow-up rates after introduction of the incentive $(p=0.2)$. Both before and after the introduction of the incentive, primary care physicians in the highest uptake quartile had the highest 14-day follow-up rates $(68.4 \%$ compared with $65.7 \%, p<0.001$; Appendix 1, supplementary Figure 10).

We performed an additional post hoc analysis of follow-up with any physician according to the primary care physician funding model because of the observed increase in enhanced fee-for-service funding in 2005. There was no effect of the incentive on any physician follow-up in any of the major funding model groups (Appendix 1, supplementary Figure 11).

\section{Interpretation}

In this time series study of patients discharged from hospital to home, a fee code to incentivize physician follow-up after hospital discharge was adopted by $51 \%$ of eligible physicians and cost an average of \$2.1 million annually. Despite this, there was no sizable impact on 14-day physician follow-up rates, or a 14-day composite of emergency department visits, readmissions or death. Physicians with the highest uptake of the incentive had the highest 14-day follow-up rates before and after the intervention, which suggests that the incentive rewarded the highest performing providers without modifying their behaviour.

Our findings show that followup rates have remained relatively stable over time, despite rising patient complexity. Other than the possibility that physician incen-

Figure 4: Proportion of patients who had an emergency department visit or unplanned readmission, or died within $14 \mathrm{~d}$ after hospital discharge, by month of discharge. Broken line indicates the introduction of the incentive code. 
tives in general may not be effective, there are several reasons that may explain the failure of this particular incentive to improve follow-up rates. ${ }^{26}$ First, incentive payments were received along with other claim payments, possibly obscuring their effect on income. Second, payments were typically received weeks to a month later, doing little to reinforce the incentivized behaviour. Third, although the value of the incentive code compared favourably to the fee claimed for a regular physician visit, this may not be enough money to matter to clinicians, particularly if postdischarge patients represent a small percentage of their practice population.

Physician incentives should be designed with attention to principles of behavioural psychology. ${ }^{36}$ In particular, lack of immediacy and mental accounting may have hindered the success of this incentive. We add another consideration: that the person who is aware of the incentive payment should also be responsible for the desirable action. In the case of follow-up, if scheduling staff are inflexible, unaware or removed from the financial gains related to early follow-up, then the incentive may fail to translate to earlier scheduled appointments. Billing agents may also insulate decision-makers from monetary gains, if they are the only ones aware that the incentive is being claimed.

Although a well-designed incentive may be motivating, without automated supporting processes, the delivery of early follow-up may be partly beyond the control of the outpatient physician. Mobility, health literacy, finances or a lack of social supports may prevent patients from reaching their appointment. Current outpatient care processes may be ill-adapted to meet the needs of functionally dependent, cognitively impaired, marginalized or socially isolated individuals. Furthermore, the patient is often the only timely messenger between inpatient and outpatient systems. Primary care physicians have reported being unaware of hospital admissions until weeks after discharge, after the window for "early" follow-up has already closed. ${ }^{21-23}$ This puts the onus on the patient to inform clinic staff of their admission to hospital and need for urgent follow-up. Patients may not know that mentioning a recent admission to hospital would trigger an earlier appointment booking. In a complex system, much of the responsibility is placed on the patient for ensuring their own continuity of care.

In the US, Medicare's codes differ from the incentive studied here in several ways. Transitional Care Management codes have a greater monetary value and are reserved for more complex patient discharges. Additionally, they are supported by an existing structure of aligned incentives operating at the hospital level, such as penalties for hospital readmissions. In this context, an incentive to outpatient physicians may be more successful, as processes would have evolved to facilitate communication between inpatient and outpatient providers.

Strengths of our study include that it is population-based, and contains comprehensive information about outcomes because of linked administrative health data. Our study captured a 12-year time period, allowing for sufficient forecasting and accounting for long-term trends. We were also able to measure uptake of the intervention directly, which is not always possible in studies of health policy interventions.

\section{Limitations}

Our study has several limitations. First, temporal confounding is a potential challenge to the validity of time series studies. Modelling was used to account for any background trends in the outcomes (including the effects of gradual changes in comorbidity over time) such that these would not confound testing of the effect of the intervention. In addition, we accounted for changes to follow-up in October 2005 (possibly because of the introduction of new medical subspecialty premium codes) by incorporating this into our models. After examining a range of characteristics and outcomes over time, as well as carefully reviewing ministry billing policy bulletins from 2005 to 2007 , we are confident that no large source of bias was missed. The consistency of our results across several sensitivity and stratified analyses is supportive. Second, it is possible that the incentive had other benefits or effects not measured here, such as allowing for longer or higher quality patient visits. Third, owing to the complexity of behavioural interventions targeting physicians, the findings in this study remain limited by their context, in a single Canadian province. These results may not be generalizable to jurisdictions with different physician payment structures. However, our findings can still offer insights to organizations designing similar incentives.

\section{Conclusion}

Despite reasonable uptake, we found no effect of an incentive on physician follow-up after hospital discharge, and no effect on subsequent visits to the emergency department, readmissions to hospital or death. We believe the code's lack of effect may be explained by certain features of the incentive (lack of immediacy and separate payment), as well as barriers to follow-up that remain beyond the outpatient physician's control. Policy-makers wishing to improve follow-up care using physician incentives should carefully consider incentive design and remaining barriers before widespread adoption.

\section{References}

1. Hines AL, Barrett M, Jiang J, et al. Conditions with the largest number of adult hospital readmissions by payer, 2011 [statistical brief no. 172]. Rockville (MD): Agency for Healthcare Research and Quality; 2014

2. van Walraven C, Bennett C, Jennings A, et al. Proportion of hospital readmissions deemed avoidable: a systematic review. CMAJ 2011;183:E391-402.

3. van Walraven C, Jennings A, Forster AJ. A meta-analysis of hospital 30-day avoidable readmission rates. J Eval Clin Pract 2012;18:1211-8.

4. Auerbach AD, Kripalani S, Vasilevskis EE, et al. Preventability and causes of readmissions in a national cohort of general medicine patients. JAMA Intern Med 2016; 176:484-93.

5. Moore C, Wisnivesky J, Williams S, et al. Medical errors related to discontinuity of care from an inpatient to an outpatient setting. J Gen Intern Med 2003;18:646-51.

6. Forster AJ, Clark HD, Menard A, et al. Adverse events among medical patients after discharge from hospital. CMAJ 2004;170:345-9.

7. Forster AJ, Murff HJ, Peterson JF, et al. The incidence and severity of adverse events affecting patients after discharge from the hospital. Ann Intern Med 2003;138:161-7.

8. Moore C, McGinn T, Halm E. Tying up loose ends: discharging patients with unresolved medical issues. Arch Intern Med 2007;167:1305-11.

9. Sharma G, Kuo YF, Freeman JL, et al. Outpatient follow-up visit and 30-day emergency department visit and readmission in patients hospitalized for chronic obstructive pulmonary disease. Arch Intern Med 2010;170:1664-70.

10. McAlister FA, Youngson E, Bakal JA, et al. Impact of physician continuity on death or urgent readmission after discharge among patients with heart failure. CMAJ 2013;185:E681-9.

11. Hernandez AF, Greiner MA, Fonarow GC, et al. Relationship between early physician follow-up and 30-day readmission among Medicare beneficiaries hospitalized for heart failure. JAMA 2010;303:1716-22. 
12. Gavish R, Levy A, Dekel OK, et al. The association between hospital readmission and pulmonologist follow-up visits in patients with COPD. Chest 2015;148:375-81.

13. Muus KJ, Knudson A, Klug MG, et al. Effect of post-discharge follow-up care on re-admissions among US veterans with congestive heart failure: a rural-urban comparison. Rural Remote Health 2010;10:1447.

14. DeLia D, Tong J, Gaboda D, et al. Post-discharge follow-up visits and hospital utilization by Medicare patients, 2007-2010. Medicare Medicaid Res Rev 2014; 4.pii: mmrr.004.02.a01.

15. Hess CN, Shah BR, Peng SA, et al. Association of early physician follow-up and 30-day readmission after non-ST-segment-elevation myocardial infarction among older patients. Circulation 2013;128:1206-13.

16. Jackson C, Shahsahebi M, Wedlake T, et al. Timeliness of outpatient follow-up: an evidence-based approach for planning after hospital discharge. Ann Fam Med 2015;13:115-22.

17. Kashiwagi DT, Burton MC, Kirkland LL, et al. Do timely outpatient follow-up visits decrease hospital readmission rates? Am J Med Qual 2012;27:11-5.

18. Misky GJ, Wald HL, Coleman EA. Post-hospitalization transitions: Examining the effects of timing of primary care provider follow-up. J Hosp Med 2010;5:392-7.

19. Shen E, Koyama SY, Huynh DN, et al. Association of a dedicated post-hospital discharge follow-up visit and 30-day readmission risk in a medicare advantage population. JAMA Intern Med 2017:177:132-5.

20. Jencks SF, Williams MV, Coleman EA. Rehospitalizations among patients in the Medicare fee-for-service program. N Engl J Med 2009;360:1418-28.

21. Arora VM, Prochaska ML, Farnan JM, et al. Problems after discharge and understanding of communication with their primary care physicians among hospitalized seniors: a mixed methods study. J Hosp Med 2010;5:385-91.

22. Kripalani S, LeFevre F, Phillips CO, et al. Deficits in communication and information transfer between hospital-based and primary care physicians: implications for patient safety and continuity of care. JAMA 2007;297:831-41.

23. Bell CM, Schnipper JL, Auerbach AD, et al. Association of communication between hospital-based physicians and primary care providers with patient outcomes. J Gen Intern Med 2009;24:381-6.
24. Scott A, Sivey P, Ait Ouakrim D, et al. The effect of financial incentives on the quality of health care provided by primary care physicians. Cochrane Database Syst Rev 2011;(9):CD008451.

25. Houle SK, McAlister FA, Jackevicius CA, et al. Does performance-based remuneration for individual health care practitioners affect patient care? A systematic review. Ann Intern Med 2012;157:889-99.

26. Mendelson A, Kondo K, Damberg C, et al. The effects of pay-for-performance programs on health, health care use, and processes of care: a systematic review. Ann Intern Med 2017;166:341-53.

27. Bendix J. Making sense of the new transitional care codes. How to maximize revenue related to the federal government's drive to reduce rehospitalizations. Med Econ 2013;90:40,2-4, 7.

28. Bulletin no. 4439. Implementation of 2004 Physician Services Agreement. Toronto: Ontario Ministry of Health and Long-Term Care; 2006.

29. Juurlink DN, Preyra C, Croxford R, et al. Canadian Institute for Health Information Discharge Abstract Database: a validation study. Toronto: Institute for Clinical Evaluative Sciences; 2006.

30. CIHI data quality study of Ontario emergency department visits for fiscal year 20042005 - executive summary. Ottawa: Canadian Institute for Health Information; 2007.

31. Shah BR, Hux JE, Laupacis A, et al. Administrative data algorithms can describe ambulatory physician utilization. Health Serv Res 2007;42:1783-96.

32. Iron K, Zagorski BM, Sykora K, et al. Living and dying in ontario: an opportunity for improved health information. Toronto: Institute for Clinical Evaluative Sciences; 2008.

33. Quan H, Sundararajan V, Halfon P, et al. Coding algorithms for defining comorbidities in ICD-9-CM and ICD-10 administrative data. Med Care 2005;43:1130-9.

34. Jandoc R, Burden AM, Mamdani M, et al. Interrupted time series analysis in drug utilization research is increasing: systematic review and recommendations. J Clin Epidemiol 2015;68:950-6.

35. Stukel T, Glazier RH, Schultz SE, et al. Multispecialty physician networks in Ontario. Open Med 2013; 7:e40-55.

36. Emanuel EJ, Ubel PA, Kessler JB, et al. Using behavioral economics to design physician incentives that deliver high-value care. Ann Intern Med 2016;164:114-9.
Competing interests: Muhammad Mamdani has received personal fees for serving as an advisory board member to AstraZeneca, Bristol-Myers Squibb, Eli Lilly and Company, GlaxoSmithKline, Hoffman-La Roche, Novartis, Novo Nordisk and Pfizer. Noah Ivers and Muhammad Mamdani have received research grants from the Ontario Ministry of Health and Long-Term Care, unrelated to the current study. Chaim Bell has received consultant fees from the Policy and Innovation Branch of the Ontario Ministry of Health and Long-Term Care. No other competing interests were declared.

This article has been peer reviewed.

Affiliations: Department of Medicine (Lapointe-Shaw, Mamdani, Redelmeier, Bell), University of Toronto; Li Ka Shing Knowledge Institute (Mamdani), St. Michael's Hospital; Institute for Clinical Evaluative Sciences (Mamdani, Luo, Austin, Ivers, Redelmeier, Bell); Department of Family and Community Medicine (Ivers), University of Toronto; Sinai Health System (Bell); Women's College Hospital (Ivers), Toronto, Ont.

Contributors: Lauren Lapointe-Shaw, Muhammad Mamdani, Peter Austin, Noah Ivers, Donald Redelmeier and Chaim Bell contributed substantially to the conception and design of the work. Lauren Lapointe-Shaw, Muhammad
Mamdani, Jin Luo and Chaim Bell contributed substantially to acquisition, analysis and interpretation of data for the work. Lauren Lapointe-Shaw drafted the manuscript. All of the authors critically revised the manuscript for important intellectual content, gave final approval of the version to published and agreed to be accountable for all aspects of the work in ensuring that questions related to the accuracy or integrity of any part of the work are appropriately investigated and resolved.

Funding: This study was supported by the Institute for Clinical Evaluative Sciences (ICES), which is funded by an annual grant from the Ontario Ministry of Health and LongTerm Care (MOHLTC). The opinions, results and conclusions reported in this paper are those of the authors and are independent from the funding sources. No endorsement by ICES or the Ontario MOHLTC is intended or should be inferred. Parts of this material are based on data and information compiled and provided by the Canadian Institute for Health Information (CIHI). However, the analyses, conclusions, opinions and statements expressed herein are those of the authors, and not necessarily those of $\mathrm{CIHI}$.

This study was supported by a Canadian Institutes of Health Research (CIHR) and Canadian Patient Safety Institute Chair in Patient
Safety and Continuity of Care to Chaim Bell, who also reports support from the Department of Medicine, University of Toronto. Lauren Lapointe-Shaw reports support from a CIHR Fellowship Award (FRN 146714) and the Eliot Phillipson Clinican-Scientist Training program at the University of Toronto. Muhammad Mamdani reports support from the Ontario MOHLTC and the CIHR Ontario SPOR SUPPORT Unit. Noah Ivers reports support from a CIHR New Investigator Award and from the Department of Family and Community Medicine, University of Toronto. Donald Redelmeier reports support from a Canada Research Chair in Medical Decision Science and a grant from the BrightFocus Foundation. Peter Austin reports support from a Career Investigator Award from the Heart and Stroke Foundation (Ontario office).

The CIHR and the Canadian Patient Safety Institute had no involvement in the design and conduct of the study; collection, management, analysis, and interpretation of the data; preparation, review, or approval of the manuscript; and decision to submit the manuscript for publication.

\section{Accepted: May 4, 2017}

Correspondence to: Lauren Lapointe-Shaw, lauren.lapointe.shaw@mail.utoronto.ca 